\title{
Kant: lo sublime teológico
}

\section{Kant: The Theologieal Sublime}

\author{
Leopoldo Tillería Aqueveque \\ Universidad Tecnológica de Chile, Santiago, Chile \\ Contacto: leopoldo.tilleria@inacapmail.cl \\ https://orcid.org/0000-0001-5630-7552
}

\section{RESUMEN}

Se sugiere la recepción de lo sublime kantiano como un sentimiento inopinadamente religioso, en otras palabras, como una estética teológica. De cara a la tercera Crítica, y con la precisión de un relojero, el viejo Kant parece equilibrar las nuevas condiciones cosmológicas, religiosas y metafísicas a las que se enfrenta el hombre barroco con la necesidad propiamente teológica de no excluir a Dios de su proyecto filosófico. De este modo, la estética kantiana se revela como fuente de lo religioso, precisamente, a partir del contacto práctico del sujeto con la idea de la divinidad. En esta región, el sujeto pensante encuentra un más allá indeterminado en el que alcanza a tocar, o, si se quiere, sentir la omnipotencia e inmensidad de Dios. Mediante la labor propedéutica de la Analítica de lo sublime, la Crítica de la facultad de juzgar vendría a completar el camino teológico trazado en la segunda Crítica por la razón pura práctica. De manera subrepticia, lo sublime teológico expondría, por un lado, la insistencia de Kant en no abjurar de su férreo puritanismo, y, por otro, su decisión de no ceder ni a la desesperación intelectual ni al terror metafísico que supone la expulsión de Dios del ámbito de la razón.

Palabras clave: Dios; Estética teológica; Juicio; Kant; Sublime

\section{ABSTRACT}

It suggests the reception of the Kantian sublime as an unexpectedly religious sentiment, in other words, as a theological aesthetics. In the face of the third Critique, and with the precision of a watchmaker, the old Kant seems to balance the new cosmological, religious and metaphysical conditions confronting baroque man with the properly theological need not to exclude God from his philosophical project. In this way, Kantian aesthetics is revealed as the source of the religious, precisely, from the practical contact of the subject with the idea of divinity. In this region, the thinking subject finds an indeterminate beyond in which he is able to touch, or, if you will, to feel the omnipotence and immensity of God. Through the propaedeutic work of the Analytic of the Sublime, the Critique of Judgment would complete the theological path traced in the second Critique by pure practical reason. Surreptitiously, the theological sublime would expose, on the one hand, Kant's insistence on not renouncing his ironclad puritanism, and, on the other, his decision not to give in to either the intellectual despair or the metaphysical terror that the expulsion of God entails from the realm of reason.

Keywords: God; Theological aesthetics; Judgment; Kant; Sublime 


\section{Introducción}

No es de extrañar que la Analítica de lo sublime, ese "simple apéndice del enjuiciamiento estético de la conformidad a fin de la naturaleza" (CFJ A77) $)^{1}$, continúe entrañando hoy cuotas de discusión estéticas, epistemológicas y hasta políticas, muchas de ellas como cavilaciones posmodernas que insospechadamente muestran la "huella" del propio Kant y de otros "maestros de lo sublime" como Schiller, Hegel o el mismo Schopenhauer. Tampoco podemos eludir la "carga moral" que la tradición le ha enquistado a lo sublime, argumento que el propio Kant se ha encargado de presentar como fruto de su segunda Crítica: "De hecho, no se puede pensar un sentimiento para lo sublime de la naturaleza sin ligar a él un temple del ánimo que es parecido al temple para lo moral" (CFJ A1 16).

En lo que sigue consideraré a la Analítica de lo sublime como una especie de sibila délfica respecto de la propia filosofía de Kant, en el sentido de que atendiendo con detención a lo sublime kantiano podría "adivinarse" buena parte del espíritu de su autor. Esta manera de enfrentar la segunda parte de la Crítica del juicio estético nos da la posibilidad de volver sobre una pregunta que a estas alturas ya es un "mito" filosófico: el papel de lo sublime en la CFJ, o, para decirlo en los términos de la filosofía crítica, el lugar de la misma CFJ en el sistema de Kant. A sabiendas de que la tarea es titánica (la figura del "monstruo de ojos azules" parece ficticia, pero es enteramente real), pondremos a prueba, pues, la arquitectónica de la tercera Crítica.

De modo que sugeriré - en lo que sería la hipótesis de este trabajo - la poco ortodoxa tesis de entender lo sublime kantiano no como un sentimiento estético, sino como uno de otra índole, seguramente no distinguible con precisión al interior de la doctrina de Kant y que tendría la potencialidad, siguiendo algunos indicios de la última Crítica, pero sobre todo la formación pietista de nuestro filósofo, de ser comprendido como religioso. Parte de mi argumentación se fundará en los desarrollos de Lyotard como comentarista de Kant y en algunas observaciones sobre lo sublime de Moses Mendelssohn, filósofo por quien Kant sintió en vida una gran admiración.
Al mismo tiempo discutiré la probable filiación barroca del filósofo de Königsberg, a partir de lo cual propondré que la Analítica de lo sublime constituiría el centro de la CFJ, o, en una afirmación todavía más arriesgada, la verdadera "propedéutica de toda filosofia". Tal posibilidad de vincular sentimiento estético y sentido religioso debiera sorprendernos siempre y cuando desconociéramos que "durante 17 siglos la reflexión estética convivió, de hecho, confundida con la ética y con la moral religiosa" (Murcia-Serrano, 2008, p. 137), y que recién a partir del trabajo de Baumgarten dicha reflexión adquirió "acta de nacimiento" como disciplina autónoma. Esta forma de entender lo sublime conectada con la idea de Dios parece hallar cierta aceptabilidad, por lo menos en la investigación trascendental, en la siguiente afirmación de Martínez Marzoa (2004), nuestro "tercer fundamento":

En cualquiera de sus nombres (de los que uno es "mundo"), la "idea" sólo puede aparecer como una consecuencia de lo descubierto en la averiguación ontológica, por lo tanto, no como una representación disponible para su manejo en esa misma averiguación. (p. 62)

Con un guiño a Heidegger, diríamos que esta heterodoxa esencialidad de lo sublime hace posible que pueda ensayarse con su obra algo aún más originario y, por tanto, no deducible desde Kant mismo. Así como en Kant y el problema de la metafisica Heidegger (1929) transforma la primera Crítica en un preámbulo para la analítica existenciaria de Ser y tiempo, en el sentido de comprender el tiempo literalmente como una protoestructura trascendental, del mismo modo lo sublime kantiano pareciera expresar un fondo ontológico en el que estética y teología muestran una determinación tan desconocida como la célebre "raíz común” insinuada por Kant en A15/B29.

\section{Lo sublime kantiano}

Más allá de que sus primeros escritos sobre lo bello y lo sublime sean una respuesta a las ideas pregóticas de Burke, la teoría kantiana de lo sublime debiera apreciarse como el intento de completar la búsqueda iniciada con la Dissertatio (1770) del modo de comprendernos subjetivamente, pero, a diferencia de las 
condiciones trascendentales postuladas por la primera y la segunda Crítica, ahora sin mediación de concepto ni de ley. Es el resultado filosófico esperado de quien se ha hecho cargo de las consecuencias gnoseológicas, teológicas y estéticas de una época, como la barroca, donde el humanismo ha sido prácticamente borrado luego de la "explosión" epistemológica del Renacimiento. Ya en plena CFJ, Kant se referirá a lo sublime en distintos pasajes del texto, unas veces como sentimiento, otras desde la perspectiva del modo en que opera dicho enjuiciamiento. Así, por ejemplo, en lo que suena como una perfecta definición emocional, dirá en el § 23:

[...] y en cambio aquélla (el sentimiento de lo sublime) es un placer que sólo surge indirectamente, a saber, de modo tal que es generado por el sentimiento de un momentáneo impedimento de las fuerzas vitales y de una tanto más fuerte efusión de ésas inmediatamente consecutiva; por tanto, no parece ser, como emoción, un juego, sino seriedad en el quehacer de la imaginación. (CFJ A75)

Enseguida describirá el juicio de lo sublime repitiendo el mismo patrón aplicado al juicio de lo bello, con la salvedad de que en la Analítica de lo sublime comenzará por el momento de la cantidad:

[...] pero habría que tomar en cuenta que allá, donde el juicio estético concernía a la forma del objeto, empezamos por la [...] cualidad, y que aquí, en cambio, dada la informidad que puede convenirle a aquello que llamamos sublime, empecemos en la cantidad [...]. (CFJ A79) do de la razón por medio de la presentación de una cierta intuición a la imaginación en cuanto facultad productiva: "Este movimiento puede ser comparado (sobre todo en su inicio) con un sacudimiento, es decir, con una repulsa y una atracción rápidamente cambiantes hacia uno y el mismo objeto" (CFJ A98). La referencia al objeto sublime produce en nuestro espíritu un verdadero desbarajuste entre la imaginación y las ideas de la razón.

Para no caer en la intrincada nomenclatura de Kant, pero sin dejar de lado su famosa división de lo sublime, digamos que sublime matemático será lo absolutamente grande para nuestra representación y sublime dinámico aquello que en la naturaleza se nos aparece con una fuerza descomunal sin que podamos oponerle resistencia alguna. Así, lo sublime matemático se presenta cuando nuestra imaginación "no da abasto" para reunir en una unidad lo dado en la sensibilidad. Lo sublime dinámico, en cambio, supone aquel sentimiento que la naturaleza provoca en nosotros en razón de su poderío irresistible. En este "lado oscuro" de las facultades superiores del espíritu, por un lado, como seres sensibles, nos sentimos incapaces de enfrentar la omnipotencia de la naturaleza, pero, por otro, como seres suprasensibles, creemos sentirnos superiores a ella al desatarse en nosotros una fuerza capaz no solo de resistirla, sino de sobrepasarla en nuestro espíritu.

Curiosamente es en este rebasamiento donde recaerá el placer negativo de lo sublime. Señala Kant:

[...] y desde que el ánimo no es sólo atraído por el objeto, sino alternativamente, una y otra vez

\section{[...] la Analítica de lo sublime es el centro de la CFJ, el lugar donde el hombre por fin podrá pensar reflexivamente la idea de Dios, encontrándose con É.}

De manera que, "cuantitativamente", el juicio de lo sublime debe ser universal; "cualitativamente", desinteresado; según la relación, finalizado subjetivamente y según la modalidad, necesario. Además, dice Kant, en lo sublime, así como en lo bello, no hay dependencia de ningún tipo de sensación, o, lo que es lo mismo, no es el objeto el sublime (el mar embravecido, la montaña, el cielo estrellado, el precipicio). Lo sublime no depende de nuestros sentidos; sí, en cambio, está referido a un concepto indetermina- repelido también, la complacencia en lo sublime contiene menos un placer positivo que una admiración o respeto, esto es, algo que merece ser denominado placer negativo. (CFJ A75)

No deja de ser sugerente la observación de Rogozinski (2016), quien ve en la exposición de lo sublime un trato "privilegiado" de Kant a propósito del lugar intermedio que ocupa esta emoción entre el asco y la belleza: 
Entre ambos goces, antitéticos, aunque sostenidos por la tensión de la imaginación, se despliega el sentimiento de lo sublime, que Kant no designa nunca como un goce, que sólo nombra la alternancia violenta y sin fin entre la atracción y el horror... (pp. 139-140)

Insospechadamente lo sublime nos revela, fundado en una descubierta libertad suprasensible, la capacidad de sobreponernos a esa naturaleza todopoderosa de la que quedamos, como quien dice, blindados por este nuevo sentimiento. Justamente es esta victoria "en nombre" de la humanidad (aunque hipotéticamente como seres humanos hayamos sucumbido de manera física ante la inmensidad y poderío de la naturaleza) la que produce ese placer que al inicio notábamos como problemático o al menos extraño. Paradójicamente es un placer fruto del dolor, pues: ¿cómo no disfrutar este triunfo inesperado frente a la potencia infinita de la naturaleza y a aquello que sobrepasa toda medida de nuestra sensibilidad? Bien podría decirse de la CFJ, parafraseando a Oyarzún (2017), que l'enfant terrible es el juicio de lo sublime.

\section{Subjetividad, infinito, Dios}

En lo sublime, el sujeto experimenta un inusual sentimiento de superioridad tras haber superado la imaginación los límites de la sensibilidad y alcanzado lo ilimitado en su "obligación" de adecuarse a la razón mediante una determinación suprasensible. Sin embargo, en algo así como un nuevo "giro copernicano", Lyotard invertirá la prioridad kantiana entre juicio determinante y juicio reflexionante, cuestión controvertida pero esencial a nuestro trabajo.

En efecto, para Lyotard la Crítica del juicio estético pone de manifiesto una forma reflexiva del pensar que atestigua, por así decir, una ontología de lo sublime esquiva al dictum estético de Kant. Es decir: los juicios verdaderamente determinantes serían los juicios reflexionantes, dado que es justo en ellos donde se experimentará "de verdad" lo subjetivo del pensamiento. De este modo, Lyotard (1998) se referirá al "pathos de lo sublime, a diferencia del calmo sentimiento de lo bello" (p. 103). Y en sus Leçons sur 1'Analytique du sublime sostendrá:
Puedo concluir que las mismas propiedades que impiden la deducción de un sujeto sublime son las que me autorizan a sostener lo sublime en el orden de lo subjetivo. Lo subjetivo puede y debe persistir como la sensación de sí mismo que acompaña todo acto del pensar en su instante. (Lyotard, 1991, p. 38) $^{2}$

De manera que la Analítica de lo sublime abre la posibilidad de una estética diferente a aquella derivada de la Analítica de lo bello, una estética con signo de divinidad:

Por otra parte, lo sublime que trasciende todos los límites y conduce la sensibilidad hacia lo suprasensible, debe necesariamente encontrar un absoluto que sobrepase el dominio propio de la estética y chocar con la representación imposible de lo incondicionado. El sentimiento de lo sublime debe, por tanto, experimentar una fuerza invencible que se eleva por encima de la sensibilidad: debe encontrarse con un dios situado más allá de cualquier representación estética humanamente posible. (Lyotard, 1991 en Darriulat, $2007, \mathrm{~s} / \mathrm{p})$

A guisa de la recepción lyotardiana de la estética de Kant, quisiera enfatizar su idea de "subjetividad sin naturaleza", idea que significa virtualmente corroborar en la Analítica de lo sublime "una estética sin naturaleza" y que parece conectarse con esta misteriosa fórmula kantiana de insinuar en lo sublime "una más elevada conformidad a fin", misma que en otros lugares de la "Analítica" llamará "contraria a un fin para nuestro juicio". Lyotard (1998) tiene razón cuando piensa lo sublime en una dirección no tanto estética como ontológica respecto de un sujeto atribulado: "Lo que falta son justamente las bellas formas con su destinación, nuestro propio destino, y lo sublime entraña esa especie de pena debido a la finitud de la carne, esa melancolía ontológica" (p. 120). El francés insistirá en que en el sentimiento de lo sublime no es el entendimiento, sino la razón, lo que exige a la imaginación la presentación sensible imposible de lo suprasensible incondicionado de lo que siente la necesidad. En otras palabras:

Resta que para Kant lo sublime artístico no es griego, sino egipcio - las pirámides - o cristiano 
- San Pedro de Roma-; preclásico o posclásico, lo sublime escapa a la perfecta belleza de los dioses griegos que radica en su exacta limitación y proporción; lo sublime kantiano pertenece más bien al arte cristiano que descubre el abismo interior del destino del hombre y busca una imagen de él en la inmensidad. (Lyotard, 1991 en Darriulat, 2007, s/p)

La interpretación de Lyotard es la de una CFJ centrada en el juicio estético como "vaciamiento" de las determinaciones práctico-epistémicas de las dos primeras Críticas, es decir, una suerte de "desmentido" acerca del mero papel de puente que tradicionalmente se le ha atribuido a la última Crítica. En mi opinión, Lyotard ha preparado el terreno de la facultad de juzgar para considerar lo estético como fuente de lo religioso justamente a partir del contacto práctico del sujeto con la idea de Dios.

Hay, sin embargo, una dificultad mayor en la teoría kantiana de lo sublime, si es que no en todo el sistema trascendental. Pues si el filósofo prusiano ha dicho en su célebre carta a Reinhold de 1787 que el sentimiento de placer y displacer tiene su principio $a$ priori en la finalidad, de esto se desprende que el juicio de lo sublime, como un caso de los juicios estéticos en general, debe también su fundamento trascendental a la teleología. Mas, como vimos, Kant duda y hasta da la impresión de que retrocede cuando se trata de presentar tal finalidad como fundamento de lo sublime, ya que unas veces la da por sentada (en el contraste de lo sublime con lo bello al comienzo de la Analítica de lo sublime), otras veces acepta la posibilidad de una conformidad contraria a un fin, y en otras pone en duda esta idea o derechamente se abstrae de ella (Conti, 2010). Esta ambigüedad parece explicarse si reconocemos que la finalidad, como el propio Kant lo concede, es en realidad un principio formal que regula el orden de las cosas de la naturaleza y el arte; esto es, nada más que una conjetura sobre la relación de las formas bellas de la naturaleza con nuestras facultades cognitivas. A decir verdad, justo lo que lo sublime no es.

Dicha observación pone una duda razonable sobre la inclusión final de lo sublime en la doctrina kantiana y, al mismo tiempo, deja las puertas abiertas a una eventual determinación entre estética y teología. Como se ve, esta idea de una "estética sin naturaleza" parece excluir de toda posibilidad de existencia al sujeto trascendental, puesto que sin naturaleza ya no se justifica una apercepción que requiera dar cuenta de la finalidad fenoménica del mundo sensible. Al contrario, demandaría una subjetividad que, en la forma del juicio reflexionante, apunte hacia lo infinito trascendental, vale decir, hacia la totalidad de todas las magnitudes dadas. Creo razonable suponer que este infinito se halla en Dios.

\section{Lo sublime como propedéutica del sentimiento religioso}

En un lugar extrañamente poco comentado de la Analítica de lo sublime, Kant pondrá frente a frente sublimidad y divinidad:

Sólo cuando es consciente de su sincero sentir grato a Dios, sirven esos efectos del poderío para despertar en él la idea de la sublimidad de ese ser, en la medida en que reconoce en sí mismo una sublimidad del sentir adecuada a la voluntad de aquél, y es, por ese medio, elevado por sobre el temor ante tales efectos de la naturaleza, que no se ve como arrebatos de ira divina. (CFJ A108)

Lo estético parece fundar una dimensión en que el sujeto pensante, mediante el pensar estético y respecto de sí mismo, encuentra un más allá indeterminado en que alcanza a tocar, o, para decirlo según nuestra presunción, sentir la omnipotencia e inmensidad de Dios. Este encuentro con lo indeterminado equivale a nuestra destinación suprasensible. Kant se halla en una encrucijada: no puede "barrer bajo la alfombra" los postulados epistemológicos de su primera Crítica, pero tampoco puede retroceder ante la posibilidad suprasensible que le abre lo sublime. Lo único que puede hacer es no caer en las aporías metafísicas de Wolff (que él mismo se ha encargado de criticar) y asegurarse, por medio de su segunda Crítica, de postular la existencia de Dios como un equivalente de la posibilidad de realización del Bien sumo. No hay otra explicación para este divagar de Kant entre las dos primeras Críticas y la tercera, ni para la incrustación en la segunda Introducción de la idea de que solo la parte estética tiene una posición fundamentante. Dicho trascendentalmente, lo que se funda es el sentimiento teológico a partir del sentimiento estético de lo sublime. 
Tal preparación se evidencia sobre todo en el trayecto de la imaginación hasta su límite:

La enormidad sublime del objeto, su desmesura, conduce a la imaginación hasta su límite, su punto de exceso en que se encuentra a punto de desfallecer, y este Überschwenglich, este exceso, este ultraje que desbarata su captación "es para ella como un abismo (Abgrund) en que teme (furchtet) perderse ella misma”. (Rogozinski, 2016, p. 134)

Ahora, esta conexión entre estética y teología se da en un plano completamente distinto al que Kant plantea en el $\S 85$ de la CFJ, en la Crítica del juicio teleológico:

[...] la idea de un ser supremo, que reposa en un uso de la razón completamente diferente [...], está a priori en nosotros como fundamento que nos impulsa a completar la defectuosa representación [que se hace] una teleología física del fundamento originario de los fines en la naturaleza, hasta [legar al] concepto de una divinidad. (CFJ A399)

Es decir, no se trataría de un argumento teleológico, menos aún de uno de carácter práctico - como sería el caso, por ejemplo, del discurso moral de la existencia de Dios - Conjeturando acerca de esta posibilidad de acceder al sentimiento religioso por tomado de la naturaleza (de nuestra alma), como inteligencia suprema, y entonces debería llamarse teología natural. (Kant, 1998, A631/B659)

Una vez presentada la prueba ontológica, concluye:

El concepto de un ser supremo es una idea muy útil en no pocos aspectos. Pero, precisamente por tratarse de una simple idea, es totalmente incapaz de ampliar por sí sola nuestro conocimiento respecto de lo que existe. Ni siquiera es capaz de informarnos sobre la posibilidad de una pluralidad. (Kant, 1998, A601/B629)

En cuanto a la prueba cosmológica, afirma Kant:

El artilugio de la demostración cosmológica tiene como único objetivo eludir el probar a priori, mediante simples conceptos, la existencia de un ser necesario; tal prueba tendría que proceder a la manera del argumento ontológico [...]. Con este fin, inferimos de un ser real [...] que nos sirve de base alguna condición absolutamente necesaria [...]. De esta forma, no tenemos necesidad de explicar la posibilidad de tal condición. (Kant, 1998, A610/B638)

Ahora bien, será la Crítica de la razón práctica la que mostrará la idea de una teología natural mediante la adecuación entre deber, existencia y bien supremo. Escribe ahí Kant (2005):

\section{[...] si la Crítica del juicio estético es la "propedéutica de toda filosofía”, yo sugeriría que lo sublime [...] nos enfrenta a la magnificencia infinita de Dios.}

vía de lo sublime, habría que señalar que la clase de teología que se muestra en esta particular sensación no parece alinearse con ninguna de las dos teologías presentadas por Kant en sus dos primeras Críticas, la teología trascendental y la teología natural. Desglosemos, pues, estas teologías "puras". En relación con la teología trascendental, en Crítica de la razón pura, el regiomontano dice:

La primera [theologia rationalis] concibe su objeto, o bien a través de la razón pura, mediante simples conceptos trascendentales (ens originarium, realissimum, ens entium), y se llama teología trascendental, o bien lo concibe, a través de un concepto
Por consiguiente, el postulado de la posibilidad del bien supremo derivado (del mejor mundo), es al mismo tiempo el postulado de la realidad de un bien supremo originario, es decir, de la existencia de Dios. Ahora bien, para nosotros era un deber el promover el bien supremo y, por lo tanto, no sólo era un derecho sino también una necesidad objetiva unida como necesidad subjetiva con el deber, el presuponer la posibilidad de este bien supremo, el cual, dado que sólo tiene lugar bajo la condición de la existencia de Dios, enlaza inseparablemente la presuposición de esta existencia con el deber, es decir, que es moralmente necesario admitir la existencia de Dios. (pp. 149-150 $<226>)^{3}$ 
Este sumo Bien tiene, decíamos, su correlato en la razón pura práctica a través de la conciencia moral. La idea práctica de Dios se sintetiza en la noción de juez moral, quien en cuanto persona ideal debe "conocer los corazones" porque el tribunal se establece en el interior del hombre y debe ser "quien obliga siempre". Es decir, los deberes han de poder considerarse como mandatos suyos. De esto debe entenderse que es la razón pura práctica de Kant, y no la religión o una presunta filosofía de la religión, la encomendada a determinar la religiosidad del hombre, religiosidad que, insiste Kant, siempre tendrá una esencia moral y no evangelizadora.

\section{Ese raro bienestar}

Estos desacomodos de "orden" teológico en el global de la arquitectónica de Kant tendrán, nolens volens, una resolución más sistemática y probablemente más "ilustrada" en su texto de 1793, La religión dentro de los límites de la mera razón, lugar donde el filósofo de Königsberg logra ensayar una dubitativa filosofía de la religión. Una de estas prescripciones es aquella mediante la cual delimita los alcances de una posible filosofía de la religión, la que, para el caso, corresponderá únicamente a la religión cristiana:

En cambio, según la Religión moral (tal es, entre todas las religiones públicas que ha habido, sólo la cristiana) es principio lo que sigue: que cada uno ha de hacer tanto como esté en sus fuerzas para hacerse un hombre mejor; y sólo cuando no ha enterrado la moneda que le ha sido dada al nacer (Luc., X IX, 12-16), cuando ha empleado la disposición original al bien para hacerse un hombre mejor, puede esperar que lo que no está en su capacidad sea suplido por una cooperación más alta. (Kant, 1981, p. 61)

Entonces, en la doctrina de la religión de Kant, el hombre, el bien supremo y Dios deben alinearse en un nuevo marco antropológico-filosófico. Por cierto, el marco "doctrinario" de la religión obedecerá en Kant exclusivamente a un conocimiento de la Razón, que no es otra cosa que el efecto de la ley moral en nosotros. El mandato divino no está, de tal modo, de lado de los legajos eclesiásticos, sino de la obediencia a la Razón:
Así pues, no hay ninguna norma de la fe eclesial aparte de la Escritura, ni otros intérpretes de ésta que la pura Religión racional y la erudición escrituraria [...], de los cuales sólo el primero es auténtico y válido para todo el mundo, mientras que el segundo es sólo doctrinal [...] (Kant, 1981, p. 116)

Sería esta algo así como una posible vía de relación con Dios, reglada, fundada y determinada por la ley moral, por la razón pura práctica y no por la naturaleza que hay en nosotros, como en el caso de lo sublime. En tal sentido resulta completamente aclarador el comentario de Sandru (2020), quien logra reconocer en la teoría kantiana de lo sublime una analogía perfecta con una cierta determinación cristológica: "This is achieved through an initial displeasure of the subject - feeling itself incapacitated in face of its evil nature - which motivates it to change its state by recognising the possibility of thinking a moral maximum" [Esto se logra a través de un disgusto inicial del sujeto - sentirse en sí mismo incapacitado frente a su naturaleza maligna - que lo motiva a cambiar de estado reconociendo la posibilidad de pensar en un máximo moral] (p. 47; traducción propia).

Ahora, ya antes que Kant, Moses Mendelssohn había sugerido la relación entre Dios y lo sublime, postulando que lo sublime era una experiencia religiosa inclusiva, no confesional y universalmente compartida (Mendelssohn podría considerarse un judío liberal), características en general coincidentes con la filosofia kantiana. Reflexionaba Mendelssohn (1999):

Este rocoso escollo que se eleva allá arriba, por encima de la murmurante corriente, tiene un aspecto horrible. La vertiginosa altura, el engañoso miedo a caer y el hundimiento con el que parecen amenazar los fragmentos que penden alrededor, nos fuerzan a menudo a apartar de él la mirada desconcertada. Sólo que, tras un pequeño alivio, volvemos a dirigir nuestros ojos a este temible objeto. La horrible vista agrada. ¿De dónde saco este raro bienestar? (p. 162)

Kant tomará de Mendelssohn la idea de inmensidad y, también, la de "sentimiento mixto". Esta consiste en el tránsito desde una sensación de terror, causada por la fuerza desproporcionada de la naturaleza, a una de complacencia en la idea de infinito, que Mendelssohn denomina - sin tapujos - instancia de 
lo divino y que por alguna extraña razón Kant decide simplemente llamar "desbordamiento de nuestras facultades". De modo que sería un error no solo suponer que Kant es quien "descubre" esta ambivalencia de sentimientos en la experiencia de lo sublime, sino sobre todo no tener en cuenta que Mendelssohn ha dejado, poco antes que el filósofo prusiano, bastante zanjado el camino para ubicar lo sublime en el campo de la divinidad.

Ya la primera Crítica había corroborado que la idea de Dios carece de un objeto como correlato, y que, por tanto, solo podemos referirnos a Él como idea. Por eso se puede decir que el ideal de la razón pura coincide con el objeto de la teología racional. Este límite trascendental a la realidad de Dios, puesto por la epistemología kantiana, muestra el fracaso de la razón pura especulativa a la hora de fundar una teología. Cosa distinta parece acontecer en el segundo paso crítico que da Kant, al intentar demostrar la existencia de Dios por la vía moral. Empero, creo que Kant trastabilla a la hora de desarrollar esta demostración, quedando "atrapado" en una racionalidad práctica que, por un lado, lo sujeta en favor de la idea aparentemente más relevante desde el punto de vista práctico-moral, como es la de libertad, y, por otro, lo empuja hacia el imperativo de la búsqueda de la felicidad. Entremedio, fortalece esta tensión práctico-teológica la exigencia racional de voluntad. $\mathrm{Al}$ "mostrarse" la idea de Dios como problemática respecto de la autonomía del sujeto libre, es bastante obvio que en la teoría ética de Kant la moral quede completamente desvinculada de la religión. Como lo postula la segunda Crítica, la religión debe subordinarse a la moral: "De este modo la ley moral, mediante el concepto del bien supremo como objeto y fin de la razón pura práctica, conduce a la religión, es decir, al conocimiento de todos los deberes como mandamientos divinos" (Kant, 2005, p. $154<233>$; cursivas del original).

\section{Estética y puritanismo}

Se ha discutido en varios lugares el posible compromiso barroco de Kant. Aquí seguiré la postura de que no solo la estética, sino su filosofía entera tendría una inclinación resueltamente barroca pese a sus coqueteos de estilo con el clasicismo o, como también se ha querido ver, con el romanticismo (Bowie, 2003; Carrasco, 2015; Warnock, 1993). Todo esto a pesar de las dificultades habidas para llegar a una definición, digámoslo así, unidimensional del mismo Barroco, tarea que a la postre resulta en extremo difícil. Sin embargo, hay un pasaje de Castany (2012) que ayudaría a esclarecer el problema:

Durante los siglos XVI y XVII, la ruptura de ciertos límites, considerados hasta entonces divinos o naturales, habría supuesto un sentimiento mezclado de liberación y vértigo, que son, mutatis mutandis, las características que Burke, Kant y Schopenhauer atribuyen a lo sublime. Mientras en el Renacimiento habría pesado más la sensación de liberación, en el Barroco habría pesado más la de vértigo y pérdida de sentido. Así, el paso del Renacimiento al Barroco puede entenderse como el paso de la claustrofobia del sentido que sentía el hombre renacentista frente al mundo medieval, a la agorafobia de la libertad que sentirá el hombre barroco frente a un mundo infinito y desordenado, dejado de la mano de Dios. (p. 93)

Se trata, en definitiva, de un sentimiento de vértigo frente a un mundo infinito, precisamente el de las emociones, que describen el abismo de lo sublime kantiano. Ahora, si reconocemos, con Trottein (1998), una tensión permanente en la primera parte de la CFJ entre una teoría de lo bello y una metafísica del arte, vale decir, entre una reflexión fundada en la idea de lo informe e ilimitado (belleza libre, música a-temática, acantilados) y una demanda más metafísica respecto del arte (el esbozo de clasificación del arte bello o la intención deductiva de un discurso sobre el arte), o bien, siguiendo nuestra suposición, entre un Kant barroco y un Kant clasicista, la balanza parece inclinarse a favor del puritanismo estético del filósofo. Dicho barroquismo se confirma en una lectura un poco más detallada de la Crítica del juicio estético. De hecho, si atendemos a algunos lugares poco estudiados de esta primera parte de la CFJ, caemos en cuenta de que esta idea de lo vertiginoso, de lo libre, de lo ilimitado, en suma, de lo infinito, se va reiterando asistemática pero persistentemente a lo largo de todo el texto. De esta clase, van apareciendo expresiones que podríamos catalogar perfectamente de barrocas: "arabescos", "tatuajes", "bellezas libres de Sumatra", 
"hojarascas", "papeles de tapizar", "diseños libres". Esto en torno a lo bello, y sobre lo sublime:

La estupefacción, lindante en el terror, el horror y el sagrado estremecimiento, que coge al espectador ante la vista de masas montañosas que suben hasta el cielo, de simas hondas y, allí, enfurecidas aguas, de páramos profundamente ensombrecidos que invitan a la meditación melancólica, etc., no es, dada la seguridad en que aquél se sabe, efectivo temor, sino sólo un intento de aventurarnos en ellos con la imaginación, a objeto de sentir, precisamente, el poder de esta misma facultad para enlazar el movimiento del ánimo provocado por ellos con el estado de reposo del mismo y sobreponernos así a la naturaleza en nosotros mismos y, con ello, también a la naturaleza fuera de nosotros [...]. (CFJ A116)

Esta ambigüedad de Kant (estupefacción/intento de aventurarnos, horror/meditación melancólica, terror/placer) pudiera explicarse tout court por el rol que le ha correspondido jugar en la historia, traducido, por un lado, en el jalón de una religiosidad barroca derivada de su formación protestante, y, por otro, en la inercia de un clasicismo racionalista alimentado por su fuerte preparación científica. Ciertamente, la complejidad del Barroco pone no solo a la filosofía, sino a la sociedad en general en la tarea nada banal de decidir qué lugar ocupa de veras el individuo en el universo. Frente a esta empresa, que corresponde a la tarea primordial de su filosofía crítica, Kant se revela, según era de esperar, como hijo de su época o, dicho sin recovecos, como un filósofo del pietismo.

Con la precisión de un relojero, el viejo Kant parece equilibrar las nuevas condiciones cosmológicas, religiosas y filosóficas a las que se enfrenta el hombre barroco (por ejemplo, la agorafobia existencial de Pascal ante el infinito) con la necesidad propiamente teológica de no excluir a Dios de su proyecto filosófico, intento que la segunda Crítica había sistematizado con las ideas trascendentales de Dios, de alma y de libertad poniendo un límite gnoseológico infranqueable en la noción de juicio práctico determinante. Este camino trazado por la razón pura práctica, que finalmente conducirá al problemático concepto de fe racional, viene a ser completado por la CFJ a través de la noción de juicio reflexionante y, en particular, por la verdadera labor propedéutica de la Analítica de lo sublime.

Lo anterior tiene implicancias teológicas cardinales, pues lo que queda a la vista a través esta extraña arquitectónica es la insistencia de Kant, a un paso del mundo suprasensible, de no abjurar de su férreo puritanismo, pero tampoco ceder ni a la desesperación intelectual ni al terror metafísico que supone la expulsión de Dios del ámbito de la razón. La sola presunción de que ante este conflicto entre imaginación y razón podamos resarcirnos en lo sublime en la completa indeterminación de cara a lo infinito, obliga a suponer que lo que Kant ha querido decir - no diciéndolo, una vez más - es sencillamente que la Analítica de lo sublime es el centro de la CFJ, el lugar donde el hombre por fin podrá pensar reflexivamente la idea de Dios, encontrándose con Él. No por nada Cassirer (1948) afirmará que en la Analítica de lo sublime "se revelan de un modo verdaderamente perfecto y en la más feliz de las combinaciones todos los aspectos del espíritu de Kant” (p. 382).

\section{Conclusión}

Las pocas aclaraciones sobre lo sublime que hizo Kant en la Crítica de la facultad de juzgar no nos autorizan, sin embargo, a restarle la importancia que tiene en la arquitectónica final de su sistema. Con la idea de lo sublime, el filósofo de ojos azules ha querido salvar esa profundidad inacabable que separa lo sensible de lo suprasensible y que tiene en el Barroco su correlato en el contraste entre las nociones de Dios y cosmos infinito. Si la CFJ vino a salvaguardar la unidad de la razón pura en la forma de un puente que uniera nóumeno y fenómeno, bien cabe suponer que la clave se halla en las pocas líneas que Kant dedicó a lo sublime. De modo que, si la Crítica del juicio estético es la "propedéutica de toda filosofia”, yo sugeriría que lo sublime, tomando las palabras de Murcia-Serrano (2008), nos enfrenta a la magnificencia infinita de Dios.

Seguramente lo que haya que destacar más es justo lo que Kant no ha querido destacar, y esto es el sustrato religioso de lo sublime. Así, el mundo suprasensible al que nos conduce lo sublime parece ser en realidad el mundo de la divinidad, o, como se lee en la segunda Crítica, el mundo en el que llegamos a to- 
car la idea de Dios. No debiera sorprendernos, pues, esta conexión entre lo sublime y lo teológico, menos aún si haciendo un esfuerzo hermenéutico llegamos a interpretar el temor y el placer de lo sublime como el temor reverencial a Dios y la experiencia conmovedora de poder representarnos su presencia. Schiller, observa Oyarzún (2017), tiene su base filosófica en el principio kantiano de finitud y en un gesto de pro- fundización de la escisión entre sensibilidad y razón, que sella a su vez una distancia infinita del hombre respecto de la divinidad como ser infinito y como infinito acuerdo de racionalidad y existencia. Al revés de esta idea del poeta alemán, lo sublime en Kant rompe esa distancia infinita respecto de Dios, en la forma precisamente de un infinito acuerdo entre razón y sentir.

\section{Notas}

1 Usamos la traducción de Pablo Oyarzún de Crítica de la facultad de juzgar (en adelante CFJ), publicada por Monte Ávila editores (Caracas, 1992). Como indica el traductor, la paginación señalada en el margen de la obra corresponde a la primera edición alemana (A) y a las ediciones segunda y tercera (B y $C$ respectivamente), que son coincidentes en ello. En este trabajo utilizaré la paginación de la edición $A$.

2 A no ser que se indique lo contrario, las traducciones de las referencias procedentes de otros idiomas son propias.

3 Entre diples se indica la paginación de la primera edición (1788).

\section{Referencias bibliográficas}

Bowie, A. (2003). Estética y subjetividad: From Kant to Nietzsche. Manchester: Manchester University Press.

Carrasco, A. (2015). American horror story: Kant, lo sublime y el terror romántico. Kritisches Journal 2.0. Revista de Filosofía sobre Idealismo y Romanticismo, 1, $80-94$.

Cassirer, E. (1948). Kant, vida y doctrina. Ciudad de México: Fondo de Cultura Económica.

Castany, B. (2012). Sublimidad y nihilismo en la cultura del Barroco. Revista de Filosofía, 2 (37), 91-110. https://doi.org/10.5209/rev_RESF.2012.v37.n2.41070

Conti, R. (2010). El sentimiento de lo sublime y el abismo de lo indeterminado en la estética de Kant. Cuadernos del Sur. Filosofía, 39, 65-84.

Darriulat, J. (2007). Introduction à la Philosophie Esthetique. http://www.jdarriulat. net/Introductionphiloesth/PhiloModerne/Kant/KantAnalSublime.html

Heidegger, M. (1929). Kant y el problema de la metafísica. Bonn: F. Cohen Editor.

Kant, I. (1981). La religión dentro de los límites de la mera razón. Madrid: Alianza.

Kant, I. (1992). Crítica de la facultad de juzgar, Trad. P. Oyarzún. Caracas: Monte Ávila Editores.

Kant, I. (1998). Crítica de la razón pura, Trad. P. Ribas. Madrid: Alfaguara.

Kant, I. (2005). Crítica de la razón práctica. Ciudad de México: Fondo de Cultura Económica.

Lyotard, J. F. (1991). Leçons sur l'Analytique du sublime. París: Galilée.

Lyotard, J. F. (1998). Lo inhumano, charlas sobre el tiempo. Buenos Aires: Manantial.

Martínez Marzoa, F. (2004). Kant y la mota de polvo. Logos. Anales del Seminario de Metafísica, 37, 55-65.

Mendelssohn, M. (1999). Sobre los sentimientos. En A. Baumgarten, G. Hamann, M. Mendelssohn y J. J. Winckelmann, Belleza y verdad. Sobre la estética entre la Ilustración y el Romanticismo (pp. 125-238). Barcelona: Alba.

Murcia-Serrano, I. (2008). De Dios y lo sublime. Anales del Instituto de Investigaciones Estéticas, 93, 137-160. https://doi.org/10.22201/iie.18703062e.2008.93.2272

Oyarzún, P. (2017). Schiller: lo sublime y la revolución de la sensibilidad. Revista de Teoría del Arte, 9, 11-50. 
Rogozinski, J. (2016). Al límite de lo ungeheure: sublime y monstruoso en la crítica de la facultad de juzgar. Revista Teoría del Arte, 8, 121-151.

Sandru, A. R. (2020). The Role of the Sublime in Kant's Religion: Moral Motivation and Empirical Possibility. Kantovskij Sbornik, 39 (1), 31-57. https://doi. org/10.5922/0207-6918-2020-1-2

Trottein, S. (1998). Esthétique ou philosophie de I'art? En H. Parret (Ed.), Kants Ästhetik (pp. 660-673). Berlín, Nueva York: Walter de Gruyter.

Warnock, M. (1993). La imaginación. Ciudad de México: Fondo de Cultura Económica. 